\title{
PREDICTION MODELING OF PHYSIOLOGICAL RESPONSES AND HUMAN PERFORMANCE IN THE HEAT
}

\author{
Kent B. Pandolf \\ U.S. Army Research Institute of Environmental Medicine (USARIEM) \\ Natick, Massachusetts 01760-5007, USA
}

\section{INTRODUCTION}

Predictive models of human heat strain are generally developed to serve specific aims and objectives. In a recent review, Werner (1) suggests that human heat strain models may be categorized into three groups: (a) thermoregulatory models which allow us to explore functional physiological mechanisms $(2,3,4)$, (b) operational models which predict human performance of industrial or military personnel $(5,6)$, and (c) clinical models designed to predict heat illness/injury and clinical treatment (7). Many of these predictive models will be discussed during the oral presentation of this article. However, computer modeling approaches to environmental ergonomics and the associated interests of this audience are probably more directly aligned to the operational models, such as the USARIEM Heat Strain Model, which predict physiological responses and human performance in the heat.

\section{USARIEM HEAT STRAIN MODEL DEVELOPMENT}

Over the last three decades, our Institute has developed a comprehensive USARIEM Heat Strain Model which has been programmed for use by hand-held calculators, personal and battlefield computers, and further incorporated into the development of a heat strain decision aid. The mathematical basis used to develop the various individual predictive algorithms/equations and the predictive capabilities of our heat strain model have been published in detail previously (6).

This operational model deals with several major input variables: (a) the predicted/preferred energy expenditure primarily associated with walking or running to include the external load, grade, speed and specific terrain, (b) the functional state of the individual in terms of being either non-heat acclimated or fully-heat acclimated, (c) the weather conditions to include the air temperature, solar load/sky conditions as in index of cloud cover, humidity and wind speed, (d) the clothing worn, and (e) if appropriate, the accepted level of heat casualties. In addition to predicting rectal temperature, sweat loss and heart rate responses given the above inputs, our model predicts the expected physical work/rest cycle, the maximum safe physical work time, the estimated recovery time (sun or shade) from maximum physical work, the time into the mission, and the associated drinking water requirements for each specific scenario. More recent or inprogress refinements of this model include the development of algorithms/equations to 


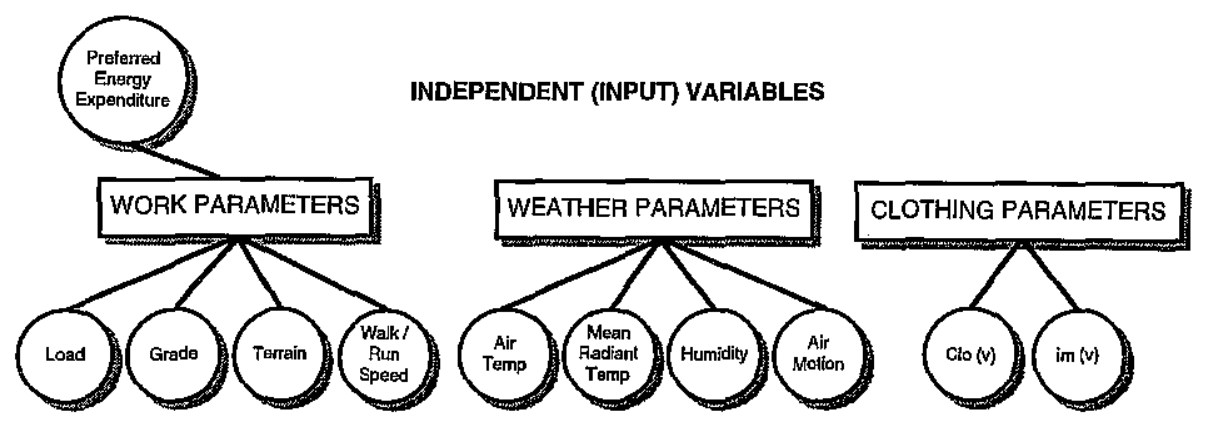

DEPENDENT (OUTPUT) VARIABLES
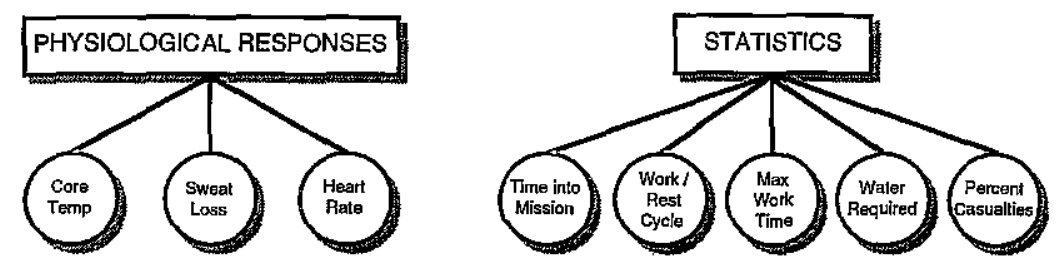

Figure 1. Schematic diagram of the major input and output variables of the USARIEM Heat Strain Model.

better predict the effects of (a) state of hydration (dehydration), (b) microclimate cooling of protective clothing, and (c) the radiant/solar load. A schematic diagram of the various independent (input) and dependent (output) variables associated with our heat strain model is presented in Figure 1.

\section{RESULTS/DISCUSSION}

With over three decades of development and refinement, the USARIEM Heat Strain Model considers a wide range of ambient temperatures from $20-54^{\circ} \mathrm{C}$, relative humidities from $10-95 \%$, and wind speeds up to $4 \mathrm{~m} \cdot \mathrm{s}^{-1}$. Hundreds of clothing systems have been evaluated ranging from light to heavy clothing of high or low permeability. Different energy expenditures from rest to heavy physical work have been studied and incorporated into our modeling capabilities.

Individual predictive equations: Predicted energy expenditure considers walking and running while carrying external loads up to $50 \mathrm{~kg}$ at grades up to $20 \%$ and the effects of the specific terrain. Terrain coefficients have been established to better characterize the walking surface and include blacktop, brush, swamp, sand and snow. The published correlation coefficients ( $r$ values) between predicted and measured energy expenditure for our walking and running prediction equations are 0.96 and 0.95 , respectively. 
Predictive equations for the time pattern of rectal temperature, sweat loss and heart rate responses to physical work, environmental conditions and clothing properties have also been published. When compared to observations from our own and other laboratories, the correlation between the predicted and measured rectal temperatures is high $(\mathrm{r}=0.83$ $0.97)$ as are values for sweat loss $(r=0.94-0.95)$ and heart rate $(r=0.97)$. Further refinements for the effects of heat acclimation on rectal temperature and heart rate responses showed good agreement between predicted and measured values for both responses (rectal temperature, $\mathrm{r}=0.96$; heart rate, $\mathrm{r}=0.94$ ).

U.S. and non-U.S. military scenarios: During a field study in Australia, predicted and observed rectal temperature responses of 12 soldiers were compared while wearing three different military clothing ensembles (U.S. BDO closed, UK NBC closed and jungle uniform) under two different outdoor climatic conditions $\left(-30^{\circ} \mathrm{C}, 62 \% \mathrm{rh}\right.$, shade; $\sim 32^{\circ} \mathrm{C}$, $41 \% \mathrm{rh}$, sun). A group independent from our Institute collected these data and found them to be in very good agreement with predicted values. In 28 out of 30 comparisons, the observed responses were within \pm 1 standard deviation (SD) of that predicted using our model (6). In another study, 23 unacclimated male soldiers attempted light or heavy exercise in a cool $\left(18^{\circ} \mathrm{C}, 50 \% \mathrm{rh}\right)$ or warm $\left(30^{\circ} \mathrm{C}, 50 \% \mathrm{rh}\right)$ environment for a proposed 300 minute exposure in Canadian Forces NBC protective clothing (8). The USARIEM Heat Strain Model predicted final rectal temperature responses within \pm 1 standard error of measurement (SEM) from that observed in three out of the four test conditions. McLellan and colleagues (8) concluded: "Thus, U.S. Army guidelines for maximal allowable work times with minimal heat casualties, based on the Pandolf et al. modeI, can be considered to be applicable to our CF Infantry NBC protective clothing".

NASA scenarios: More recently (9), the utility of the USARIEM Heat Strain Model was shown for three NASA scenarios involving the Launch and Entry suit (LES). The LES was modeled during (a) pre-launch/launch, (b) re-entry and landing, and (c) emergency egress after re-entry and landing mostly to evaluate the effects of heat acclimation and dehydration (9). During the pre-launch/launch scenario, final predicted rectal temperatures were in good agreement with observed values depicting minimal heat strain (rectal temperature $-38^{\circ} \mathrm{C}$ ). However, dehydrated (3\%)-unacclimated individuals were predicted to exhibit moderate levels of heat strain for this same scenario (rectal temperature $\sim 38.5^{\circ} \mathrm{C}$ ). During the two other scenarios, the separate and combined effects of dehydration and lack of heat acclimation were more pronounced and predicted to produce excessive heat strain (rectal temperature $>39^{\circ} \mathrm{C}$ ). Tolerance time was predicted to be only six minutes during emergency egress when individuals were dehydrated and unacclimated to heat.

\section{CONCLUSIONS}

The major individual predictive equations incorporated into the USARIEM Heat Strain Model have been shown to provide good agreement with measured values and as 
demonstrated for rectal temperature accurately predict responses (generally within \pm 1 SD/SEM) for a wide variety of different scenarios. This model can also be used to predict the expected physical work/rest cycle, the maximum safe physical work time, the estimated recovery time from maximal physical work and the drinking water requirements given the particular physical work, environmental conditions and clothing properties.

\section{ACKNOWLEDGEMENTS AND DISCLAIMER}

The author wishes to acknowledge the expert technical assistance of Mr. Julio A. Gonzalez and Ms. Edna R. Safran, and the advice of Drs. Richard R. Gonzalez and Kenneth K. Kraning in preparing this manuscript. Approved for public release; distribution is unlimited.

\section{REFERENCES}

1. Werner, J. 1996, Modeling homeostatic responses to heat and cold, in M.J. Fregley and C.M. Blatteis (eds.), Handbook of Physiology: Environmental Physiology (Oxford University Press, New York), 613-626.

2. Gagge, A.P. 1973, Rational temperature indices of man's thermal environment and their use with a 2-node model of his temperature regulation, Federation Proceedings, 32, 1572-1582.

3. Stolwijk, J.A.J. and Hardy, J.D. 1977, Control of body temperature, in Handbook of Physiology: Reaction to Environmental Agents (American Physiological Society, Bethesda), 45-67.

4. Wissler, E.H. 1985, Mathematical simulation of human thermal behavior using whole body models, in A. Shitzer and R.C. Eberhart (eds.), Heat Transfer in Medicine and Biology: Analysis and Applications (Plenum Press, New York), 325-373.

5. Belding, H.S. and Hatch, T.F. 1955, Index for evaluating heat stress in terms of resulting physiological strains, Heating, Piping \& Air Conditioning, 27, 129136.

6. Pandolf, K.B., Stroschein, L.A., Drolet, L.L., Gonzalez, R.R. and Sawka, M.N. 1986, Prediction modeling of physiological responses and human performance in the heat, Computers in Biology and Medicine, 16, 319-329.

7. Reardon, M.J. 1995, A prototype computer program that integrates predictive models and medical handbooks for altitude, cold exposure, and heat stress, U.S. Army Research Institute of Environmental Medicine, Report No. T95-11.

8. McLellan, T.M., Jacobs, I. and Bain, J.B. 1993, Influence of temperature and metabolic rate on work performance with Canadian Forces NBC clothing, Aviation, Space, and Environmental Medicine, 64, 587-594.

9. Pandolf, K.B., Stroschein, L.A., Gonzalez, R.R. and Sawka, M.N. 1995, Predicting human heat strain and performance with application to space operations, Aviation, Space, and Environmental Medicine, 66, 364-368. 